\title{
City and Building Designers, and Climate Adaptation
}

\author{
Catherine Dubois ${ }^{1}$ * , Geneviève Cloutier ${ }^{2}$, Maja Karoline Rosenkilde Rynning ${ }^{3}$, Luc Adolphe ${ }^{3}$ \\ and Marion Bonhomme ${ }^{3}$ \\ 1 Centre de recherche en aménagement et développement (CRAD), Laval University, Pavillon Félix-Antoine \\ Savard, local 1612, 2325 rue des Bibliothèques, Université Laval, Québec City, QC G1V 0A6, Canada \\ 2 École supérieure d'aménagement et de développement régional (ESAD), Laval University, Pavillon \\ Félix-Antoine Savard, local 1616, 2325 rue des Bibliothèques, Université Laval, \\ Québec City, QC G1V 0A6, Canada; genevieve.cloutier@esad.ulaval.ca \\ 3 Laboratoire de recherche en architecture (LRA), École nationale supérieure d'architecture de \\ Toulouse (ENSA), 83 rue Aristide Maillol, BP 10629, 31106 Toulouse Cedex 1, France; \\ maja-karoline.rynning@toulouse.archi.fr (M.K.R.R.); luc.adolphe@insa-toulouse.fr (L.A.); \\ marion.bonhomme@toulouse.archi.fr (M.B.) \\ * Correspondence: catherine.dubois@utoronto.ca
}

Academic Editor: Chengzhi Peng

Received: 6 June 2016; Accepted: 25 July 2016; Published: 28 July 2016

\begin{abstract}
For cities, climate change is a major concern due to its severe impacts and its inherent complexity. City and building designers could be pivotal actors, but have yet to fully take on this role. Research can support adaptation action through greater collaboration with practitioners and a better understanding of their knowledge and practices. This paper presents results from a research project undertaken in Toulouse (France) last year. Urban practitioners were consulted through an online survey and observed in action during two design workshops. The findings highlight: (i) the hidden knowledge within design practice; (ii) the importance of providing designers with solution-focused and form-giving data; and (iii) the potential offered by design constraints to trigger changes in the practices of professionals.
\end{abstract}

Keywords: climate adaptation; city and building design professionals; design knowledge; design constraints; design tools

\section{Introduction}

Climate change is a recent, complex, and ill-defined problem typical of what Rittel and Webber [1] called a "wicked problem for planning." Climate change occurs in various places and at different scales (sea level rise, wildfires, cloudburst, drought, heat waves, etc.). However, there are many uncertainties regarding its probable impacts and their time horizon, and the effectiveness of proposed solutions. It is also widely acknowledged that climate change governance must include both adaptation and mitigation strategies $[2,3]$.

Recent development in research on adaptation planning and action argues for the co-production of knowledge between scientific and non-scientific stakeholders [4,5] that is consistent with societal needs [6,7] and is problem-oriented [8]. In order to plan and produce adaptation measures that are socially relevant, attention has been given to the process through which various stakeholders produce different types of contributions $[4,9,10]$. Involving operators, managers, citizens, elected representatives, business people, etc. in climate change governance and research would generate further support adaptation action [11]. It would also better connect scientific knowledge with adaptation needs [8].

This paper builds on the argument that increasing the involvement of non-scientific stakeholders in research on and action for adaptation can provide leverage for successful adaptation to climate 
change at the local level. It focuses on the potential role of city and building designers (e.g., architects, landscape architects, urban planners, engineers) as pivotal actors in climate adaptation. Indeed, these professionals are constantly addressing serious problems in their work. We assert that they can draw on four "catalysts for action" that can strengthen the built environment's resilience to climate change. These include interventions on (i) Urban form; (ii) Natural cover; (iii) Architecture; and (iv) Coating material. In addition, such interventions can contribute to the reduction of greenhouse gas (GHG) emissions, particularly in the transportation and building sectors. In sum, designers have the potential to act on both mitigation and adaptation through the decisions they make.

However, it has been argued that design practices have barely integrated climate adaptation [12,13]. Several questions arise from this observation. Are designers concerned with climate adaptation? What exactly do they know about it? Eliasson [14] reported an important gap between research and practice that hinders designers from engaging with scientific knowledge. Bridging this gap is critical if they are to become pivotal actors in climate adaptation. To do so, research must gain better insight into the kinds of information professionals seek when designing. Where do they find it? How should such knowledge be presented to suit their actual needs?

The following paper presents findings from the research project entitled "CapaCity: From Knowledge to Action for a Proactive Adaptation of Cities," which took place in the Toulouse region (France) in 2015. The main objectives of the study were to: (i) assess the current adaptation knowledge of city and building professionals; (ii) pinpoint the types, format, and sources of the data they use in a design process and; (iii) evaluate to what extent elements known as "design constraints" and "guiding principles" can influence the final design of an urban project.

The paper is structured around three sections. The first section highlights some of the challenges related to climate adaptation that impede city and building designers from carrying out their work. Ways to reduce these barriers and thus encourage practitioners to step in by building on characteristics from the design process are discussed. Problems of knowledge transfer between research and practice are further explored before examining the particular aspects of the designers' knowledge profile. The second section describes the applied research method, which includes an online survey completed by 115 professionals working in the Toulouse Region, and two workshops bringing together 18 practitioners from the same area. The third section presents the combined results of the survey and the workshops. They offer an overall view of the understanding designers have of climate change issues and underline the importance of research to provide solution-focused and form-giving data in line with a typical design process. These findings are discussed in light of existing barriers to adaptation. They provide further insight into how city and building designers can potentially take on a more important role in adapting cities to climate change.

\subsection{Constraints to Draw on}

City and building designers represent pivotal actors to address climate change, but have yet to fully take on this role. Various barriers continue to prevent proper action by hindering efficient collaboration between stakeholders. The complexity of climate change and climate governance, local requirements to climate adaptation, and a 'gap' between research and practice are some of the main challenges to overcome [15-17]. However, among these are potential elements to draw on for stronger climate action.

Through the last decade, substantial progress has been made within both public policy and science regarding climate adaptation $[8,10]$. Still, many uncertainties remain concerning future climate changes, their actual impacts, and the real efficiency of novel solutions [3,18]. For example, an information deficit and a difficulty in deciding between alternative planning scenarios are potential barriers for action. Perceiving the urgency of anticipating climate change impacts, and trusting that national regulatory systems and various professionals have the ability to handle the impacts, further complicate the situation $[13,19,20]$. The need for significant investments today and over the longer term in return for expected, although dubious, benefits [21] is yet another challenge. Furthermore, in order to integrate 
climate adaptation with other urban, social, and spatial dimensions, project management, governance, and regulations must be modified. This requires time and political will [22,23]. Organizational references such as building codes, urban planning bylaws, and professional liability insurances need to be reviewed and might call for new services. This can be challenging as numerous actors are involved (businesses, professional associations, international, national, and municipal authorities, etc.) and handle such reviewing processes according to their own agendas and priorities [3].

Taking a closer look at the design profession, spatial barriers affect the extent to which designers may implement adaptive actions. Local contexts are highly specific in their geographic, climatic, and urban characteristics. As a consequence, particular adaptation strategies may not be as easily imported as mitigation ones. For example, reducing GHG emissions, no matter how or where, will always be an efficient way to mitigate climate change. In contrast, extensively increasing the number of trees to reduce urban heat islands is more feasible in a mid-density, mid-latitude city than in a high-density city facing perennial water shortages. However, this points to an interesting potential. Constraints such as the geographical and regulatory contexts of a site are elements practitioners can definitely draw on to develop a project. Such elements, known as design constraints, may be used to prompt city and building designers to consider climate adaptation.

As stated by Lawson [24], constraints in a design process represent the required or desired relationship between various elements of a project. Constraints are either internal or external, and related to the designer's guiding principles. Internal constraints are client-generated and establish inner connections for the object being designed. Room types, surfaces, and numbers, as well as the objectives found in the brief, can serve as illustrations of this type of constraint. External constraints relate the design object to its context (urban, economic, cultural, environmental, political, regulatory, social acceptability, etc.). They are highly significant and exist prior to a commission, and so designers have no control over them. In a series of 36 interviews conducted with Norwegian architects, Tøsse [13] reported that a good design practice, based on local assessment, allowed them to address climate adaptation. They also stressed the importance for clients and authorities to induce radical changes in the building industry. According to the interviewees, climate adaptation will take place only if building regulations are changed. This illustrates the great potential of internal or external constraints in supporting professional practices towards a climate adaptation approach.

Guiding principles [24,25] represent another important constraint type. Understood as the intellectual baggage, the collection of ideas, beliefs, and values that a designer considers key in his domain and that is likely to grow and evolve over time, guiding principles have a significant impact on the design process. They are in part influenced by education and, for this reason, integrating climate adaptation along with other sustainability issues in the design curricula could trigger the engagement of future professionals [26]. Through semi-structured interviews conducted with architects whose work shows strong features of bioclimatic integration, Maciel and colleagues [27] demonstrated that formal education had contributed to the inclusion of passive strategies as part of their "design philosophy," or, said differently, part of their "guiding principles" [24,25].

Finally, differences between research and practice pose a challenge to knowledge transfer and collaboration [28]. For some time, the scientific community has aspired to inform city and building designers, raise awareness, and engage them with climate adaptation. Although there exists a substantial and rapidly developing body of knowledge on climate adaptation, studies have shown that practitioners have a partial understanding of the matter and its related issues [27,29-31]. The studies conducted and the tools developed so far have had little application [32-36]. There is a marked contrast between the scientific body of information and the existing social, political, organizational, and cognitive contexts. Lemos and colleagues [37] (p. 789) highlight that what scientists might see as "useful" information does not necessarily correspond with what professionals see as "usable." Based on this, we believe that taking into consideration the particular ways in which designers gain knowledge might help us understand how research could support adaptation through city and building design. 


\subsection{Designers Are Solution-Oriented, Experience-Based Knowers}

Policy-makers hold different perspectives than scientists [7,38,39]. A similar distinction can be made between the framing of scientists and designers. The former are specialists, often examining well-defined problems with a problem-focused strategy. By contrast, the latter are generalists, dealing with difficult, ill-defined problems using a solution-focused approach [24]. Their knowledge of potential solutions builds over time, through various experiences. That is why we argue that designers are solution-oriented, experience-based knowers.

Solutions are central to the knowledge acquired by designers. In the early phases of a design process, they allow them to "frame" a problem, set its boundaries, and focus attention on a limited number of elements and relations, all while moving forward cohesively [40,41]. Suggesting and testing solutions also enable designers to deepen their overall understanding of the problem, as this tends to make apparent connections and interdependencies between various elements. In a project, the main solutions sought out by the designers are those paramount in determining form [24]. They are simple, but manage to simultaneously address many aspects of the problem. For scientists, consequently, transposing their findings on climate adaptation into a series of concrete design solutions could provide a promising way to bridge the gap between research and practice.

For city and building designers, the knowledge of solutions generally comes from: (i) their previous experience, education, and intuitive sensibilities; (ii) the experience of other people; (iii) existing research; and (iv) new data and research used to supplement their initial skills [42,43]. Moreover, knowledge rooted in the acquired experience of a designer takes two forms: (i) a capability to recognize potential solutions based on design problems previously encountered; and (ii) a reliance on rules of thumb to rapidly evaluate the performance of a proposed solution. Lawson [25], drawing from the idea of "design gambits" or 'knowing what might work', explains that experienced practitioners have a greater capacity to identify certain features of design problems through similar solutions than through the abstract definition of the problem itself. They appear to recognize the type of answer that is suitable to a given design inquiry, based on their awareness of what has worked previously [44,45]. For that reason, such elements, known as "precedents", "references", and "types" form an important part of the knowledge acquired by designers [41,46]. Being whole or partial solutions, they offer a straightforward and pragmatic way to link problems to solutions and to accelerate thinking by avoiding lengthy analytical thought [42]. Likewise, "rules of thumb," which refer to principles with broad applications not meant to be strictly followed, but rather used as "quick-fix" solutions to a design problem, are another manifestation of the experience-based skills of practitioners [24].

All things considered, climate adaptation continues to present city and building designers with many challenges, but among these are constraints to further draw on too. Our premise is that their solution-focused and experience-based knowledge can support adaptation action and that a better understanding from the scientific community of their way of thinking and acting could increase their collaboration on this issue.

\section{Discovering What Designers Know and How They Work}

In 2015, the CapaCity team consulted city and building professionals working in the Toulouse region by means of an online survey and two design workshops. The region is home to 748,149 inhabitants spread over a territory of $460 \mathrm{~km}^{2}$. It is located in the southwest of France (latitude $43^{\circ} 36^{\prime}$ $\mathrm{N}$ ). On a typical summer day, the air temperature fluctuates between $15^{\circ} \mathrm{C}$ (early in the morning) and $30{ }^{\circ} \mathrm{C}$ (late in the afternoon), but may rise above $40^{\circ} \mathrm{C}$ occasionally. Studies conducted by Mété France revealed that average annual temperatures have increased by $1.3^{\circ} \mathrm{C}$ between 1945 and 2007. Average annual rainfall has decreased by $16 \%$ between 1977 and 2007. This trend is expected to continue. It is anticipated that by 2100 the climate of Toulouse should be similar to the present climate in the south of Spain. Faced with such drastic changes, the impacts of heat waves, droughts, and floods are of particular relevance for climate adaptation. 
Against this background, the objectives of the study were to:

- Assess the current knowledge of practitioners with regards to climate adaptation.

- Target the information (what, where, and how) practitioners seek out when designing.

- Evaluate to what extent design constraints and guiding principles influence the design of a project.

\subsection{Online Survey}

A total of 2660 letters of invitation were sent by email to practitioners via three professional networks collaborating with the "CapaCity" team (Appendix A). The survey, available for six weeks on an online open source platform, was comprised of two sections and included 11 questions (Appendix B). The first section provided information to establish a general profile of the respondents (age, gender, education, employment category, professional experience, and project types), while the second section dealt specifically with the research objectives. In all, 115 practitioners anonymously completed the questionnaire. It is possible that people with a specific interest in climate change and sustainability would be more likely to respond to the survey. Even so, since the aim of this phase of the CapaCity research was to assess how and with what data designers address climate change adaptation, we took into account the possibility of bias.

A statistical analysis of the results was performed. Of the respondents, $53 \%$ were men and $47 \%$ were women. They fell into the following age groups: $34 \%$ were under 35 years old, $21 \%$ were between 35 and $44,26 \%$ were between 45 and 54 , and 19\% were 55 or older (Figure 1a). The vast majority $(76 \%)$ had obtained a degree in architecture, planning, or landscape, although some had a background in engineering ( $7 \%)$, social sciences (13\%) (geography, sociology, economics, law, history, etc.), or other disciplines (4\%) (ecology, arts, interior design, geobiology, etc.) (Figure 1b).

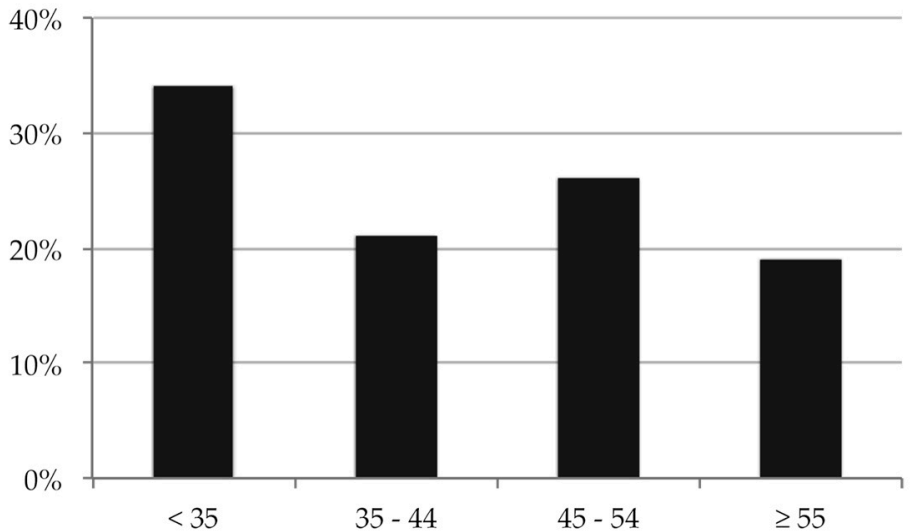

(a)

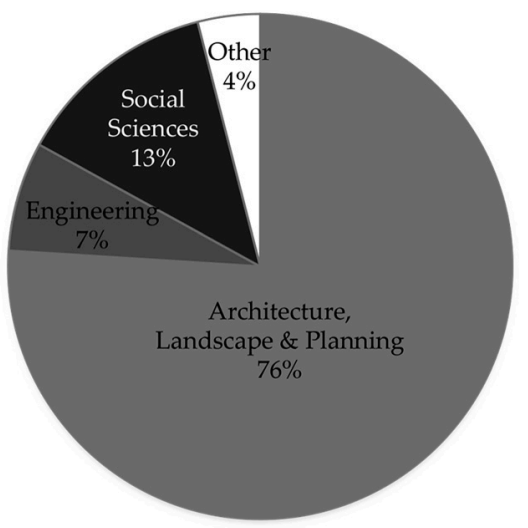

(b)

Figure 1. (a) Age distribution; (b) educational background.

The respondents were experienced practitioners; many (35\%) had careers spanning more than 20 years, and only $17 \%$ entered the job market less than five years ago. For the rest, the professional experience ranged between 10 and 14 years (19\%), 5 and 9 years (17\%), and 15 and 20 years $(12 \%)$ (Figure 2a). Most were currently employed by architectural, landscape, or planning agencies $(71 \%)$, although some worked for public bodies (15\%), engineering firms $(7 \%)$, or other consulting businesses $(4 \%)$. The others (3\%) worked for organizations of various types (university, NGO, art studio, etc.) (Figure $2 b)$. They mostly worked either exclusively at the architectural (51\%) or the urban scale (31\%), but some were regularly engaged on both scales (19\%). Their activity was centred in the residential $(20 \%)$ and civic building sectors $(18 \%)$, a combination of both $(22 \%)$, or a blend of residential and commercial structures (17\%). 


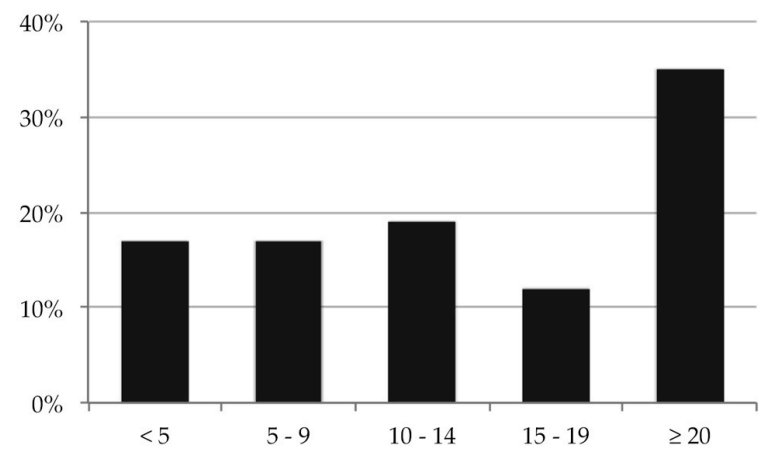

(a)

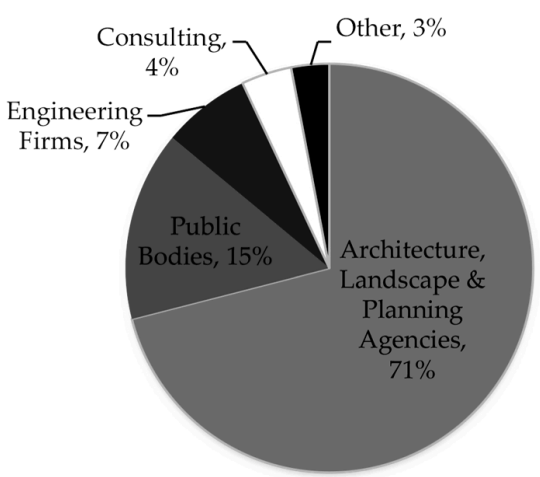

(b)

Figure 2. (a) Professional experience; (b) employment category.

As discussed further in Sections 3.1 and 3.2, the results of the survey showed, a bit to the surprise of the research team, that practitioners on the whole turn to standard online databases rather than to specialized software that can address climate change issues when seeking information at an early stage of the design process. Moreover, respondents who agreed to be contacted to participate in the workshop, and are therefore more likely to have a greater awareness of climate change, also showed preference for standard reference tools. In other words, the survey showed a low level of utilization of tools specifically conceived to support design for climate comfort. This reinforced the relevance of the workshop formula in order to highlight practical needs in terms of knowledge acquisition and modes of communication.

\subsection{Design Workshops}

Two design workshops were held at the "École Nationale Supérieure d'Architecture de Toulouse" in May and June 2015. The first convened six practitioners (two men and four women), and the second formed a group of 12 (eight men and four women). More information on their profession and employment categories can be found in Table 1. All of the participants were recruited through the online questionnaire, and 66 out of the 115 respondents left their contact information by answering the final question. They were contacted either by email or by telephone. In the end, however, only 18 were recruited, mainly due to pressing time schedules.

Table 1. Profile of workshop participants.

\begin{tabular}{|c|c|c|c|c|}
\hline \multirow{2}{*}{ Profession } & \multicolumn{2}{|c|}{ Workshop 1} & \multicolumn{2}{|c|}{ Workshop 2} \\
\hline & Private & Public & Private & Public \\
\hline - Architect & 1 & & 7 & \\
\hline - Architect and planner & 1 & & 1 & \\
\hline - Planner & & 2 & & \\
\hline - Engineer & & 1 & & 1 \\
\hline - Geobiologist & 1 & & & \\
\hline - Architect and professor & & & & 1 \\
\hline - Sociologist and professor & & & & 1 \\
\hline - Landscape architect and professor & & & & 1 \\
\hline Total & & & & \\
\hline
\end{tabular}

The design workshops consisted of two phases: a one-hour introduction, and a design game completed in two hours. The agenda for the introduction included: (i) registration, during which participants received information kits (name tag, schedule, research consent form, etc.); and (ii) a 35-min talk explaining the scope and objectives of the CapaCity project, and presenting adaptive strategies relevant for the future climate of the greater Toulouse area. This introduction to possible climate adaptation strategies undoubtedly framed the context in which participants were asked to 
launch their discussions. However, each surely had at least some interest and experience in the topic since they all volunteered to attend to the workshop, which was described as a way to discuss and even improve knowledge on climate adaptation. In other words, we assumed the possible influence that prior framing exerted at the start of the workshop. Some remarks throughout the workshops confirmed that participants had developed a keen interest in the issue raised by the research team organizing the workshops (e.g.,: "Furthermore, the focus has to be put on energy savings and all ... "). In order to reduce this bias, the second phase of the workshop consisted of a game that put into play a variety of urban dimensions.

The design game asked participants to work in multidisciplinary teams, following a set of rules (Figure 3a) explained and enforced by a facilitator. The different backgrounds of the participants favoured the exchange of information and brought them to question their priorities for the project. As a result, team members were able to integrate new knowledge and propose novel ideas. Teams of three or four were formed prior to holding the workshops to ensure they would be more or less comparable in terms of: age, gender, professions, employment categories, and experience. As in a "standard" design process, the task was to establish a design proposal for "La Cité Blanche," an existing urban renewal project located in Toulouse. The revitalized neighbourhood was to become a model of climate adaptation. To reach this goal, the projects had to satisfy the three following criteria: (i) energy efficiency for buildings and transportation; (ii) outdoor and indoor comfort for citizens; and (iii) overall water efficiency. The brief included: 400 apartment dwellings, 200 parking spaces, and one public place, as well as pedestrian and bicycle paths.

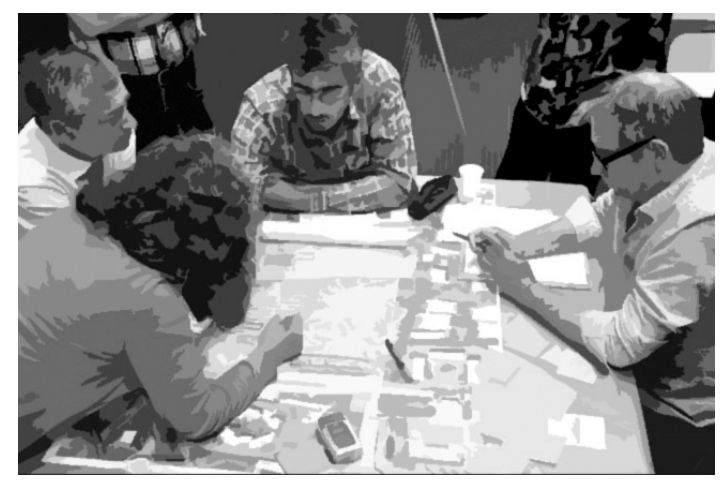

(a)

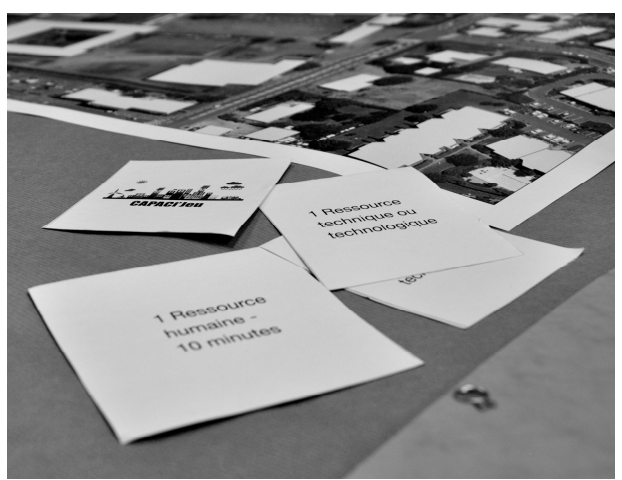

(b)

Figure 3. (a) Team in action; (b) playing cards used.

The multidisciplinary teams (Figure 3a) were asked to compose with basic information and the following materials: the Cité's site plan (1:500), aerial and Google Street View® photographs, some historical and socioeconomic facts, localization of public amenities, tracing paper, Post-its, a ruler, and markers of different colours. They could also access complementary data and resources using six "playing cards" (see Table 2) that were allocated to them at the beginning of the design game (Figure 3b).

Table 2. Playing cards offered for each resources category.

\begin{tabular}{|c|c|c|c|}
\hline Technical & Technological & Expert & Client \\
\hline $\begin{array}{ll}\text { - } & \text { Complementary maps, } \\
\text { - } & \text { Architectural magazines, } \\
\text { - } & \text { Specialized manuals. }\end{array}$ & $\begin{array}{ll}\text { - } & \text { Internet access, } \\
\text { - } & \text { ArcGIS@, } \\
\text { - } & \text { Infraworks } \odot, \\
\text { - } & \text { ArchiWIZARD } \odot, \\
\text { - } & \text { GoogleEarth } \odot, \\
\text { - } & \text { SketchUp@ }\end{array}$ & $\begin{array}{l}\text { - } \quad \text { Energy and Transportation, } \\
\text { - Landscaping, } \\
\text { - } \quad \text { Climate adaptation. }\end{array}$ & $\begin{array}{l}\text { - Manager of the Cité's } \\
\text { renewal project. }\end{array}$ \\
\hline \multicolumn{2}{|c|}{3 cards-unlimited access to the resources } & \multicolumn{2}{|c|}{3 cards-10-minute discussion } \\
\hline
\end{tabular}


As shown in Table 2, three of the playing cards allowed teams to consult either "technical" or "technological" resources. This included, for instance, complementary maps and architectural magazines placed in the middle of the room, or access to the Internet or various software programs. Those cards could be played at any point of the game, and the information they contained could be utilized anytime afterward. The three "human resources-related" cards included two "expert cards," permitting a 10-minute discussion with the consultant of their choice, and a "client" card that gave access to additional information from the manager of the Cité's renewal project. A set time limit ensured that all teams had the opportunity to discuss with any key informant at some point of the design game.

Furthermore, the teams had to deal with unpredictable events in the course of the design game, as the facilitator had seven "joker cards." Whenever used, they compelled a designated team to integrate additional design goals in their proposal. For instance, one card specified that renewable energy devices had to remain invisible from the street due to citizen complaints. Another referred to a new building regulation for which $50 \%$ of the apartments had to be cross-ventilated. These cards were a way for the facilitator to remind teams of various elements related to climate adaptation that might not have been discussed up to this point in the game.

Creating a scheme in less than two hours is a challenging task, especially when considering the fact that team members (i) came from various disciplinary backgrounds; (ii) had different experiences, and had never worked together before; (iii) were not well acquainted with the Cité's context; (iv) had limited access to information resources; and (v) had to compose with playing cards and design objectives most likely new to them. Ideally, the design game would have taken place during a two-day design charrette, but participants were only available for half a day. This latter constraint is consistent with other design studies that found it difficult to involve experienced designers due to their busy work schedules [25].

For this reason, the two-hour design game had to allow for simplifications compared to a normal design proposal. As a minimum, teams had to draw the general layout of their proposal (streets, paths, buildings, parking, public spaces, etc.) (Figure 4a), and could optionally produce other drawings such as schematic cross-sections and elevations (Figure 4b). In addition, they had to note all strategies they believed were related to climate adaptation on Post-its (Figure 4a), which were of no consequence even if they were disproved in the end.

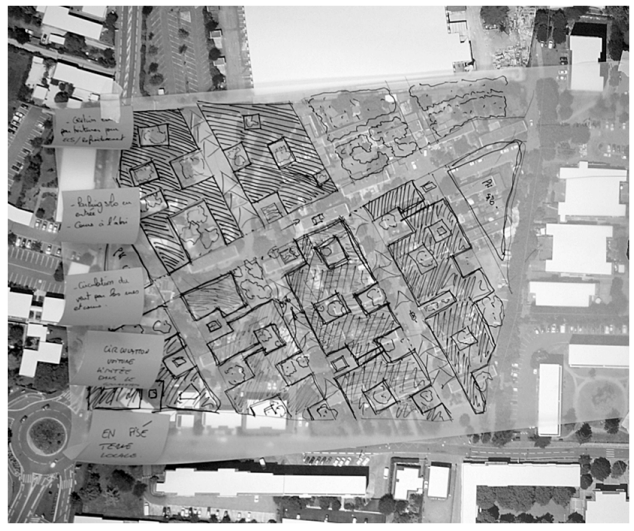

(a)

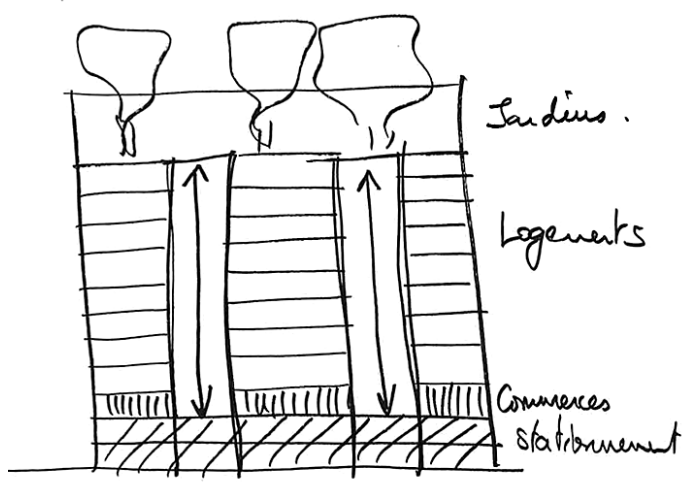

(b)

Figure 4. (a) Team's proposal; (b) complementary drawings.

A recording of each team was made throughout the entire design game until its completion (Figure 3a). Photographs were used to document specific aspects related to the design game such as the playing cards (Figure 3b), or a close-up to follow the evolving scheme. The discussions were transcribed, and a content analysis was conducted on elements pertaining to designers and climate adaptation (part 1). Video recordings, photographs and written Post-its were used as complementary sources of information only. 


\section{Designers and Climate Adaptation: Findings and Discussion}

The following sections present a cross-analysis of the online survey responses and design game observations. First we discuss the current knowledge of city and building designers with regards to climate adaptation (3.1). Second, the information (type, place, format) sought in the early stages of a design process is examined (3.2). Finally, we evaluate the influence of design constraints as well as guiding principles on the design of a project (3.3).

\subsection{City and Building Designers and Climate Change: What Do They Know?}

According to the data obtained from the survey, city and building designers are apparently concerned with climate change. The five most influential environmental issues raised in a project design process are: urban sprawl (17\%), buildings' energy consumption $(16 \%)$, mobility and transportation $(14 \%)$, urban microclimates $(11 \%)$, and natural resource management $(10 \%)$. Apart from the last item, these energy-related issues can all be linked to climate mitigation actions because they directly or indirectly impact GHG emissions [47-50].

A discourse analysis was conducted on the transcriptions obtained from the five workshop teams. According to the reflective activity literature, the remarks can be identified as "actions," "knowing-in-action," and "solution-oriented actions" [24,40]. More precisely, ideas put forward by team members were classified according to the following categories: (i) explicit adaptation measures; (ii) implicit adaptation solutions; (iii) mitigation measures; and (iv) design solutions unrelated to climate change. It appears the participants knew how to reinforce the adaptation of the Cite to climate change. As an example, one team discussed the possibility of cooling down the area by enhancing the ventilation of the site through an orientation of the street network in accordance with the prevailing winds. This is consistent with what Tøsse [13] described: architects feel they have the ability to handle the demands of climate adaptation since integrating local climatic conditions to the design process is an integral part of what is seen as "good building" design.

For the most part, however, participants did not directly link their actions to adaptation, nor did they distinguish between adaptation and mitigation measures. Solutions explicitly linked to climate adaptation comprised: "public spaces combined to sustainable urban drainage infrastructure," "cross-ventilating all housing units," and "creating a collection of small water bodies" to reduce flood and excessive heat risks. The "reinforcement of the neighbourhood green spine" and the "integration of urban agriculture elements" are examples of implicit adaptive actions. Indeed, recordings revealed that strengthening market gardening at the local level was an important part of the solution proposed by one of the teams. These greening initiatives could also reduce the Cité's exposure to certain climatic risks. Such explicit and implicit adaptation measures might have been inspired by the talk given at the beginning of the design workshops (Section 2.2), or stemmed from personal experience.

What is of greater interest is how the majority of the solution-oriented content pointed directly to a general improvement of the living environment of future inhabitants. From the viewpoints of practitioners, climate change was related to other issues including economic viability, safety, and aesthetics. Still, they did address it throughout the global reflection on the urban project.

Going back to the initial question of whether or not city and building designers are concerned with climate adaptation, what conclusions can be drawn from these findings? Considering our panel of participants who volunteered, it would seem that they broadly shared this concern from the onset. The answers to the online survey and the observations made throughout the design workshops demonstrate that designers already take into account various environmental issues that give rise to climate mitigation and adaptation actions. In fact, their knowledge of ways to tackle this serious problem appears to be greater than expected, even if a design idea is rarely justified "in the name of" adaptation. Climate adaptation is simply considered as one of several design-related concerns. Should this implicit integration of adaptation be made explicit? Could associating a design action to a specific climate adaptation target improve knowledge transfer between research and practice? We reflect on these questions through an exploration of the nature of information used by survey respondents and workshop participants. 


\subsection{The Kinds and Sources of Design Knowledge to Support Climate Adaptation}

In order to develop effective, design-oriented climate adaptation data and tools, research must gain a better understanding of the kind of information designers seek out when designing, and what their preferred sources are. How should it be presented to suit their needs?

What? As shown in Table 3, the majority of survey respondents assert they very often use regulatory documents (81\%), city and building plans $(75 \%)$, and aerial photographs $(73 \%)$ as well as topography and hydrography plans (59\%). The information found in such documents belongs to "external constraints" that directly impact the spatial resolution of a design problem (Section 1.1). Several practitioners reported very often or often having recourse to construction permits $(70 \%)$, public transit plans $(68 \%)$, and historic information $(60 \%)$. This is supported by observations from the design workshops. Although teams had access to basic information regarding the site of the project, they systematically played a "technical resources card" early on in the process in order to access complementary documents: site, transit facilities, topography and hydrography plans, as well as a bird's eye view of the neighbourhood.

Table 3. Most-used sources of information in the early stages of design.

\begin{tabular}{lll}
\hline Very Often & Very Often or Often \\
\hline - Regulatory documents $(81 \%)$ & & \\
- City \& building plans $(75 \%)$ & - Construction permits $(70 \%)$ \\
- Aerial photographs $(73 \%)$ & - Public transit plans $(68 \%)$ \\
- Topography \& Hydrography plans $(59 \%)$ & - & Historic information $(60 \%)$ \\
\hline
\end{tabular}

Where? According to the survey analysis, and based on findings from a previous study [12], the kind of information practitioners seek in the early stages of design can easily be found online in urban databases, or might be offered in a digital format by their client. Observations made throughout the design workshops add another perspective that is consistent with the literature. Designers rely chiefly on the knowledge they already possess or on the skills of their colleagues (Section 1.2). This experience-based knowledge was expressed in reference to: (i) personal anecdotes; (ii) design gambits; (iii) precedents; and (iv) rules of thumb. The experienced practitioners made extensive use of design gambits (Section 1.2) to address features of the Cité's renewal. For instance, increasing the overall safety of the neighbourhood was often explored. Without exception, all teams decided to add streets, pedestrian alleys, and bicycle paths to open up the currently isolated site. The professionals knew that such design solutions would augment the flow of people inside the block, and by extension make public spaces safer. Similar solutions have successfully been implemented elsewhere as part of French Cité's renewal initiatives over the past 20 years. The following quote highlights this awareness:

"It is important to open up public spaces and to connect them to transit axes in order to generate a consistent flow of passers-by and ensure their safety."

As for climate adaptation design gambits, they were not as straightforward. Even if many features of the proposals were suitable, it seemed the practitioners were uncertain of their efficiency. When asked, most of them were unable to tell, based on their experience, if the solutions they were putting forward would work because they had never tried them out before. One key characteristic of design gambits is that they take time to gain legitimacy, while climate adaptation is a rather recent issue.

The five teams often referred to urban and architectural precedents to suggest whole or partial solutions towards adapting the Cité to increasing temperatures. Based on their experience and their intuitive sensibilities, they were able to imagine solutions for the future of Toulouse. This can be summed up by one of the participants, who said he had travelled to Morocco and suggested the following at the urban scale: 
"Maybe we could let the traditional cities of the Maghreb inspire us? They know, in the Maghreb, how to deal with extreme heat: streets are deep and narrow and canvas is sometimes stretched over public spaces to provide extra shade in the hottest days."

In this particular case, the team decided to draw inspiration for their proposal from a typical North African urban form. In other cases, participants took partial ideas from iconic buildings such as Le Corbusier's Cité Radieuse and added features to support climate adaptation. The following excerpt speaks for itself:

“... a vertical garden city. We take the Unité d'Habitation in Marseille, we add plants, gardens, and the latest high-tech green devices and there we are."

Rules of thumb also stood out as an important demonstration of the experience-based knowledge of designers, building upon previous urban and architectural projects. All teams applied rules of thumb to dimension blocks, roads, buildings, and car parks. Indeed, the most experienced participants showed fluency in addressing such operational issues. The pre-dimensioning allowed an assessment of the performance of the proposals in respect to the brief and the urban renewal objectives (Section 2.2). However, none referred to a climate-related rule. Is it because such rules of thumb do not exist yet, or because the designers were unaware of them?

The design workshops revealed the extent to which the professionals were prone to choose a direct access to information, in a face-to-face setting. Despite the technical and technological resources available, all teams prioritized 10-minute discussions with various experts through the use of their "human resources cards." These results support a study conducted by Dubois [12], who reported that practitioners resorted to design-aid tools only when they thought they, or any of their colleagues, had insufficient knowledge or experience on a given matter. Kirkeby [51] found similar preferences through extensive interviews with architects regarding their use of knowledge in a design process. In this case, one participant described having direct access to an expert as a possibility to "jump several steps forward."

The experiment was conducted in a context that departs from reality, since city and building designers rarely have the expertise at hand. To deepen their knowledge of climate adaptation, they must turn towards other information sources. How then do professionals find useful information to the design process? Responses to items 9, 10, and 11 of the survey (Section 2.1) provide useful insight. Sixty percent of respondents indicated they very often or often use methodological guides (including manuals, technical papers, and websites) to find general and relevant information on environmental issues. In stark contrast, 77\% say they seldom or never use GIS software (ArcGIS, OrbisGis, MapInfo, etc.) for comprehensive geographic analysis (Table 4). That being said, two declared they were referring very often to online mapping tools such as Google Earth $\odot$ and Géoportail $\odot$. The conveyed geographic data seems to satisfy the designers' basic needs for information, that is to say, the site's elements that impact the spatial resolution of a project.

Table 4. Most-used tools when tackling environmental issues.

\begin{tabular}{lll}
\hline Very Often or Often & \multicolumn{2}{l}{ Seldom or Never } \\
\hline - $\quad$ Methodological guides $(60 \%)$ & - & Numerical simulation tools $(92 \%)$ \\
- Simplified computation tools $(53 \%)$ & - & GIS software $(77 \%)$ \\
\hline
\end{tabular}

With regards to assessing the performance of a design, 106 of 115 respondents declared they seldom or never use numerical simulation tools (Pleïade comfie, Archiwizard, Ecotect, Dialux, IES). This survey result is consistent with the study conducted by Dubois and colleagues [52] highlighting that although designers acknowledge the precision of such tools, they also recognize important challenges: (i) the difficulty of selecting and accessing appropriate software; (ii) the need to have high-skilled staff 
to run them; (iii) the expertise required to produce and analyse valuable outputs. One consultant on bioclimatic architecture mentioned operating such tools to perform thermodynamic appraisals. This tends to demonstrate that numerical simulation tools are usually the reserve of experts. Likewise, in a study on digital tools used by architects for solar design, Horvat and Kanters [53] revealed that although a great variety of related tools exist today, they are not suitable for the early design stages. This may explain why more than half of the respondents often use simplified computation tools (e.g., tables, graphs, spread sheets, rules of thumb).

Finally, questions 10 and 11 provide insight into the degree of appreciation and non-appreciation of design-aid tools by professionals. Their simplicity, efficiency, user-friendliness, design interface, simulation capacity, and holistic approach are particularly valued. Problems of interoperability and incompatibility, complexity, costs, time, and inflexibility are emphasized as difficulties and barriers. These findings corroborate those of previous studies [35,52]. They also show the challenge of creating appropriate tools to inform the design process given the fact that the needs expressed by users have remained relatively unchanged over time while developers have yet to come up with the right solution [35].

Hence, when looking at ways to raise climate adaptation awareness and provide professionals with useful design-oriented information, what, where and how it should be presented remain open questions. First, our study reveals the down-to-earth nature of city and building designers. Observations from the design workshops suggest that the primary data used by designers is solution-focused and form-giving. Second, designers value teamwork. They seem to rely mainly on their experience-based knowledge or on their peers. For expert knowledge, face-to-face exchanges are a first option, but consulting simple, efficient, and user-friendly tools is also appreciated.

\subsection{Increasing the Engagement by Professionals towards Climate Adaptation through Design Constraints and Guiding Principles}

If architects and planners are to play a more important role in climate adaptation, what could be implemented, and on what time horizon? To explore this question, the workshops were analysed from the perspective of internal and external constraints as well as guiding principles proposed by the various teams (Section 1.1). Based on our findings, we hypothesize that these elements could be converted into a series of concrete actions to increase the engagement by professionals towards climate adaptation in the short, medium, and long term. Quotes related to both internal (brief and client objectives) and external constraints (site analysis, regulations, social acceptability, etc.), and to guiding principles (ideas, beliefs, and values important in the domain) were captured and classified (Table 5).

Table 5. Examples of constraints and principles enunciated by participants.

\begin{tabular}{cc}
\hline Quote & Type \\
\hline "Positive-energy buildings are part of the brief." & Internal constraint \\
"Locals accept buildings four or five storeys high, but high-rises are not welcome." & External constraint \\
"Pedestrians should be prioritized. Traffic-calming measures are therefore essential." & Guiding principles \\
\hline
\end{tabular}

External constraints were the most frequent and diverse type of constraints identified. Indeed, all teams extensively discussed constraints related to access to the site and transportation modes, the profile of inhabitants, and the site's natural and built environment. Other constraints pertaining to local climate, public services, technical feasibility, and the Cité's history also marked the majority of the debates, although to a somewhat lesser degree. Finally, more than half of the teams would at some point touch on project budget issues, the potential hazards, and actual regulations. Only a few referred to politics and climate adaptation per se.

A detailed examination of the sequence through which the teams (all five) identified external constraints shows some trends. They first focused on constraints that impacted the form and organization of the project. This took up on average the first $15 \mathrm{~min}$ of the design game, discussing issues of access and transportation, natural and built constraints, climate integration, and services offered. Table 6 contains 
an example of a recorded and transcribed sequence. Next, the multidisciplinary teams would address external constraints that appeared to be less form-giving (socio-economic profile, history, politics), but still influential in the decision-making process. The example found in Table 5 ("high-rises are not welcome") expresses a team's concern for the social acceptance of the project. This constraint was important enough for the team to decide not to work on that kind of building.

Table 6. Excerpt from an external constraints identification sequence.

\begin{tabular}{cc}
\hline Actions & External Constraint Type \\
\hline North location. & Climate \\
Bus routes, bicycle paths and railway localization. & Access and transportation \\
Activities and services found in the neighbourhood. & Service offer \\
Street pattern and block assessment. & Built environment \\
\hline
\end{tabular}

In comparison, teams spent little time questioning the brief or the project's targets (internal constraints, Section 2.2). In fact, for every 10 constraints mentioned, eight were external and two were internal. However, the latter seem to have exerted a greater influence on the final design proposal, and the teams were cautious in addressing the brief. On several occasions, they would momentarily stop the design process in order to count the number of parking spaces and apartment dwellings to make sure their project complied with the brief. If this was not the case, they rapidly looked at other solutions in order to adjust. Only one team decided not to respect the brief after several unsatisfactory attempts:

"400 dwellings (200 per hectare) is not appropriate; it goes beyond the site's capacity."

The greater number and diversity of external constraints had a downside, however. Although teams identified, discussed, and agreed upon certain issues in the first phases, some of them turned out to be dropped or forgotten later in the design process. The complexity of the design problem likely drove participants to negotiate and prioritize among external constraints as the project's definition advanced. The following quotes are especially revealing:

"It's weird, you are recreating a kind of permeability on the western edge where we previously decided to have a continuous façade."

(Participant \#1)

"Wait, we can design very nice gable walls and add an alley of trees to suggest a continuous front that will accompany pedestrians. That way, the main façades of our buildings will be facing south."

(Participant \#2)

The design game also underlines the influence of guiding principles in conceiving a design project. Participants used them to suggest a solution, to build a case, or to question an idea brought up by a teammate. The example shown in Table 5 reflects a participant's position after her team discussed car-accessible roads across the site as a way to open it up. Her strong opposition to this idea is a manifestation of her belief that a car-free, pedestrian-friendly neighbourhood is important in order to create a good living environment.

Compared to external constraints, the impact of guiding principles appears to be more important. Professionals will rarely abandon the principles they embrace unless they are convinced to do so. The design workshops recorded some fierce debates, as the following excerpt demonstrates:

"The actual street layout (running north-south) works fine. We can easily add pathways to connect the subway to the train station." 
"But this is bad for the buildings' orientation. They are facing west! As an architect, I care for the occupants' comfort. As temperatures are rising, we need to protect dwellings from the sun and let the wind cool them. We ought to change the street layout to an east-west direction!"

(Participant \#2)

The second participant convinced her colleague to abide by her guiding principles. So, despite having spent $30 \mathrm{~min}$ and many design decisions needing to be reviewed, the team agreed on an indisputable north-south building orientation from this point on. This illustrates how influential guiding principles may be.

In sum, the design game showed the importance of internal and external constraints as well as guiding principles in a design process. The majority of teams (four out of five) followed internal constraints diligently. The transposition of climate adaptation targets into the brief could certainly bring a greater number of architects and planners to engage more actively within a short-term period. All teams also referred abundantly to external constraints, and most of these played a major part in the final designs. A possibility here is for various authoritative bodies to create specific external constraints related to climate adaptation in order to support design professionals in the medium term: the contractual documents signed with the client, planning bylaws and building codes integrating performance thresholds, subsidies, media exposure, design competitions, and so forth. Furthermore, the design workshops showed the key role of guiding principles in the decision-making process. However, beliefs and values were formed over longer periods of time. Therefore, communicating on climate change in a more "designerly" way [46], and providing architects and planners with more hands-on adaptation experiences, should encourage them to make a stronger and longer term commitment.

\section{Conclusions}

The aim of the survey and the workshops from the CapaCity project was to further develop the idea of city and building designers as pivotal actors engaged towards climate adaptation. These participatory approaches helped to confirm existing barriers to adaptation action, assess the current level of adaptation knowledge of practitioners, identify the kinds and the sources of that knowledge, and distinguish elements that are influential in a design process.

We acknowledge that the total number of survey respondents is rather small, and the number of design workshop participants is even smaller. As mentioned above, these relatively low sizes come with certain methodological limits. Thus, the reported results must be used and interpreted with caution. We think that reproducing this experiment in the future by means of an online survey conducted with a broader sample and in different cities, alongside a multidimensional workshop unrelated to climate change, could eliminate potential framing bias and emphasize the easiness of implementation of adaptive solutions due to their broad and intertwined character. However, the studies featured in Sections 1.1 and 1.2 tend to demonstrate that designers, even if they come from different backgrounds, think and act in a similar way when dealing with challenging problems such as climate adaptation. Based on this finding, we feel confident that our results provide interesting indications of the needs and trends of designers that can be used to imagine solutions that will strengthen urban adaptive capacity.

First, and in line with Tøsse [13], our results illustrate that architects, urban designers, planners, and engineers are concerned with climate change. According to the responses from the online survey, the environmental issues they consider the most when designing influence climate mitigation and adaptation actions. The design workshops also showed how often they chose efficient solutions without emphasizing their climate-friendly potential. This aspect was simply interwoven with other issues. In addition, they highlighted that solution-focused and form-giving data is the cornerstone of the design process. We therefore argue that providing city and building designers with holistic and operational information on the four catalysts for climate action [52], through the development 
of knowledge transfer tools such as roadmaps [12], is a promising way to bridge the gap between research in climate adaptation and practice.

Second, and in accordance with the literature [24,40], our observations highlight the extent to which internal and external constraints as well as the personal experience, beliefs, and values of designers determine project development. Increased leverage stemming from political, economic, and regulatory contexts more inclined towards climate adaptation could help professionals uphold this issue. When rules are instituted, designers generally build on them. Such constraints act as the spark plug of adaptive design. Moreover, improving the education and training of professionals by organizing, for instance, specialised design games and seminars, could heighten their awareness, confidence, and will in addressing climate change.

We believe that considering city and building designers as important, pivotal actors in climate adaptation can contribute significantly to solving the issue of climate adaptation at the local level. In the near future, tools and methodological frameworks developed for designers and readily used by them will surely enhance the adaptive capacity towards a changing climate of an increasing number of neighbourhoods and buildings.

Acknowledgments: This research is supported by ADEME, the French Environment \& Energy Management Agency. The Ethics Committee for Research Involving Humans of Laval University approved it (code: 2014-219). The authors also wish to thank Frédéric Bonneaud, Serge Faraut, Bernard Ferriès, Anne Péré and Corinne Sadokh, our colleagues and members of the project CapaCity. Finally, authors are indebted to the participants and to three anonymous reviewers for their comments.

Author Contributions: C.D., G.C., and M.B. conceived the online survey and the design workshops; C.D. M.K.R.R., M.B., and L.A. facilitated the workshops; C.D., G.C., and M.K.R.R. analysed the data; C.D., G.C., and M.K.R.R. wrote the paper.

Conflicts of Interest: The authors declare no conflict of interest.

\section{Appendix A}

Three professional networks collaborated with the "CapaCity" team: the Midi-Pyrénées Planners Association, the Midi-Pyrénées Architects Association, and the École Nationale Supérieure d'Architecture de Toulouse Alumni. 


\section{Appendix B}

The following table presents the online survey questions and response choices (Section 2.1).

\begin{tabular}{|c|c|c|c|c|}
\hline \multicolumn{5}{|l|}{ Online survey layout } \\
\hline \multicolumn{5}{|l|}{ 1. Are you? } \\
\hline$\square A$ man & $\square$ A woman & & & \\
\hline \multicolumn{5}{|l|}{ 2. How old are you? } \\
\hline$\square<35$ & $\square 35-44$ & $\square 45-54$ & $\square \geqslant 55$ & \\
\hline \multicolumn{5}{|c|}{ 3. In which business category do you currently work? } \\
\hline $\begin{array}{l}\square \text { Landscape } \mathcal{E} \\
\text { planning agencies }\end{array}$ & $\square$ Architectural firms & $\square$ Public bodies & $\square$ Engineering firms & $\begin{array}{l}\square \text { Other } \\
\text { (Specify) }\end{array}$ \\
\hline \multicolumn{5}{|c|}{ 4. What is your educational background? } \\
\hline $\begin{array}{l}\square \text { Architecture } \\
\square \text { Economics }\end{array}$ & $\begin{array}{l}\square \text { Engineering } \\
\square \text { Other (Specify) }\end{array}$ & $\square$ Geography & $\square$ Sociology & $\square$ Landscape \\
\hline \multicolumn{5}{|c|}{ 5. How many years have you been practising as a professional designer? } \\
\hline$\square<5$ & $\square 5-9$ & $\square 10-14$ & $\square 15-19$ & $\square \geqslant 20$ \\
\hline \multicolumn{5}{|c|}{$\begin{array}{l}\text { 6. On what kind of projects do you mostly work? } \\
{[\text { Text box] }}\end{array}$} \\
\hline \multicolumn{5}{|c|}{ 7. Select and rank the five environmental issues you consider the most when designing. } \\
\hline $\begin{array}{l}\square \text { Mobility } \mathcal{E} \\
\text { Transportation }\end{array}$ & $\begin{array}{l}\square \text { Buildings' energy } \\
\text { consumption }\end{array}$ & $\begin{array}{l}\square \text { Renewable energy } \\
\text { production }\end{array}$ & $\square$ Air quality & $\square$ Noise \\
\hline$\square$ Biodiversity & $\begin{array}{l}\square \text { Mobility \& } \\
\text { Transportation }\end{array}$ & $\square$ Urban sprawl & $\begin{array}{l}\square \text { Urban } \\
\text { microclimates }\end{array}$ & $\square$ Stormwater \\
\hline$\square$ Waste & $\begin{array}{l}\square \text { Natural resources } \\
\text { management }\end{array}$ & $\square$ Other (Specify) & & \\
\hline \multicolumn{5}{|c|}{ 8. How often do you use the following sources of information when designing? } \\
\hline $\begin{array}{l}\square \text { City \& building } \\
\text { plans }\end{array}$ & $\square$ Aerial photographs & $\begin{array}{l}\square \text { Natural, Industrial } \\
\text { hazard maps }\end{array}$ & $\begin{array}{l}\square \text { Maps of protected } \\
\text { natural areas }\end{array}$ & $\begin{array}{l}\square \text { Sound levels } \\
\text { map }\end{array}$ \\
\hline$\square$ Public transit plans & $\square O D$ surveys & $\square$ Climate data & $\begin{array}{l}\square \text { Socio-economic } \\
\text { information }\end{array}$ & $\begin{array}{r}\square \text { Topography \& } \\
\text { hydrography plans }\end{array}$ \\
\hline $\begin{array}{l}\square \text { Historical } \\
\text { information }\end{array}$ & $\begin{array}{l}\square \text { Construction } \\
\text { permits }\end{array}$ & $\begin{array}{l}\square \text { Planning regulatory } \\
\text { documents }\end{array}$ & $\square$ Other (Specify) & \\
\hline \multicolumn{5}{|c|}{ 9. How often do you use the following tools when working on an environmental issue? } \\
\hline $\begin{array}{l}\quad \square \text { Methodological } \\
\text { guides }\end{array}$ & $\begin{array}{l}\square \text { Simplified } \\
\text { computation tools }\end{array}$ & $\square$ GIS software & $\begin{array}{r}\square \text { Numerical } \\
\text { simulation tools }\end{array}$ & $\begin{array}{l}\square \text { Other } \\
\text { (Specify) }\end{array}$ \\
\hline \multicolumn{5}{|c|}{$\begin{array}{l}\text { 10. What are the qualities you appreciate the most in design-aid tools? } \\
\text { [Text box] }\end{array}$} \\
\hline
\end{tabular}

\section{References}

1. Rittel, H.W.J.; Webber, M.M. Dilemmas in a general theory of planning. Policy Sci. 1973, 4, 155-169. [CrossRef]

2. Intergovernmental Panel on Climate Change (IPCC). Climate Change 2014: Impacts, Adaptation, and Vulnerability. Part A: Global and Sectoral Aspects. Contributions of Working Group II to the Fifth Assessment Report of the Intergovernmental Panel on Climate Change; Field, C.B., Barros, V.R., Dokken, D.J., Mach, K.J., Mastrandrea, M.D., Bilir, T.E., Chatterjee, M., Ebi, K.L., Estrada, Y.O., Genova, R.C., et al., Eds.; Cambridge University Press: New York, NY, USA, 2014.

3. Ouranos. Towards adaptation. Synthesis on climate change knowledge in Québec; Ouranos: Montréal, QC, Canada, 2015; p. 49.

4. Cloutier, G.; Joerin, F.; Dubois, C.; Labarthe, M.; Legay, C.; Viens, D. Planning adaptation based on local actors' knowledge and participation: A climate governance experiment. Clim. Policy 2015, 1-17. [CrossRef]

5. Moser, S.C.; Boykoff, M.T. Successful Adaptation to Climate Change: Linking Science and Policy in a Rapidly Changing World; Routledge: London, UK, 2013.

6. Moser, S.C. Now more than ever: The need for more societally relevant research on vulnerability and adaptation to climate change. Appl. Geogr. 2010, 30, 464-474. [CrossRef]

7. O'Brien, K. Global environmental change II: From adaptation to deliberate transformation. Prog. Hum. Geogr. 2012, 36, 667-676. [CrossRef] 
8. Swart, R.; Biesbroek, R.; Lourenço, T.C. Science of adaptation to climate change and science for adaptation. Interdiscip. Clim. Stud. 2014, 2, 1-8. [CrossRef]

9. Adger, W.N.; Dessai, S.; Goulden, M.; Hulme, M.; Lorenzoni, I.; Nelson, D.R.; Naess, L.O.; Wolf, J.; Wreford, A. Are there social limits to adaptation to climate change? Clim. Chang. 2009, 93, 335-354. [CrossRef]

10. Ford, J.D.; Berrang-Ford, L.; Paterson, J. A systematic review of observed climate change adaptation in developed nations. Clim. Chang. 2011, 106, 327-336. [CrossRef]

11. Bulkeley, H.; Broto, V.C.; Edwards, G.A.S. An Urban Politics of Climate Change: Experimentation and the Governing of Socio-Technical Transitions; Routledge: New York, NY, USA, 2015.

12. Dubois, C. Adapter les Quartiers et les Bâtiments au Réchauffement Climatique; une Feuille de Route Pour Accompagner les Architectes et les Designers Urbains Québécois. Ph.D. Thesis, 2014.

13. Tøsse, S.E. Concern and Confidence. Architects Making Sense of Climate Adaptation. Environ. Plan. B Plan. Des. 2014, 41, 24-38. [CrossRef]

14. Eliasson, I. The use of climate knowledge in urban planning. Landsc. Urban Plan. 2000, 48, 31-44. [CrossRef]

15. Mastrandrea, M.D.; Heller, N.E.; Root, T.L.; Schneider, S.H. Bridging the gap: Linking climate-impacts research with adaptation planning and management. Clim. Chang. 2010, 100, 87-101. [CrossRef]

16. Nalau, J.; Preston, B.L.; Maloney, M.C. Is adaptation a local responsibility? Environ. Sci. Policy 2015, 48, 89-98. [CrossRef]

17. Preston, B.L.; Rickards, L.; Fünfgeld, H.; Keenan, R.J. Toward reflexive climate adaptation research. Curr. Opin. Environ. Sustain. 2015, 14, 127-135. [CrossRef]

18. Hallegatte, S. Strategies to adapt to an uncertain climate change. Glob. Environ. Chang. 2009, 19, $240-247$. [CrossRef]

19. Burton, P.; Mustelin, J. Planning for Climate Change: Is Greater Public Participation the Key to Success? Urban Policy Res. 2013, 31, 399-415. [CrossRef]

20. Moser, S.C.; Ekstrom, J.A. A framework to diagnose barriers to climate change adaptation. Proc. Natl. Acad. Sci. USA 2010, 107, 22026-22031. [CrossRef] [PubMed]

21. De Perthuis, C.; Hallegatte, S.; Lecocq, F. Economie de L'adaptation au Changement Climatique: Rapport du Conseil Economique pour le Développement Durable; Ministère de l'Écologie, de l’Énergie, du Développement durable et de la Mer: Paris, France, 2010.

22. Glaas, E.; Jonsson, A.; Hjerpe, M.; Andersson-Sköld, Y. Managing climate change vulnerabilities: Formal institutions and knowledge use as determinants of adaptive capacity at the local level in Sweden. Local Environ. Int. J. Justice Sustain. 2010, 15, 525. [CrossRef]

23. Orderud, G.I.; Winsvold, M. The role of learning and knowledge in adapting to climate change: A case study of Norwegian municipalities. Int. J. Environ. Stud. 2012, 69, 946-961. [CrossRef]

24. Lawson, B. How Designers Think: The Design Process Demystified, 4th ed.; Architectural Press: Oxford, UK, 2006.

25. Lawson, B. What Designers Know; Elsevier/Architectural Press: Amsterdam, The Netherlands, 2007.

26. Iulo, L.D.; Gorby, C.; Poerschke, U.; Nickolas Kalisperis, L.; Woollen, M. Environmentally conscious design-Educating future architects. Int. J. Sustain. High. Educ. 2013, 14, 434-448. [CrossRef]

27. Maciel, A.A.; Ford, B.; Lamberts, R. Main influences on the design philosophy and knowledge basis to bioclimatic integration into architectural design-The example of best practices. Build. Environ. 2007, 42, 3762-3773. [CrossRef]

28. Vogel, C.; Moser, S.C.; Kasperson, R.E.; Dabelko, G.D. Linking vulnerability, adaptation, and resilience science to practice: Pathways, players, and partnerships. Glob. Environ. Chang. 2007, 17, 349-364. [CrossRef]

29. Dubois, C.; Bergeron, O.; Potvin, A.; Adolphe, L. Adapting cities to climate change: Heat and urban form. In Proceedings of the 8th International Conference on Urban Climates and the 10th Symposium of the Urban Environment, Dublin, Ireland, 6-10 August 2012.

30. Moss, R.H.; Meehl, G.A.; Lemos, M.C.; Smith, J.B.; Arnold, J.R.; Arnott, J.C.; Behar, D.; Brasseur, G.P.; Broomell, S.B.; Busalacchi, A.J. Hell and high water: Practice-relevant adaptation science. Science 2013, 342, 696-698. [CrossRef] [PubMed]

31. Soebarto, V.; Hopfe, C.; Crawley, D.; Rawal, R. Capturing the views of architects about building performance simulation to be used during design processes. In Proceedings of the BS2015: 14th Conference of International Building Performance Simulation Association, Hyderabad, India, 7-9 December 2015. 
32. Bierbaum, R.; Smith, J.B.; Lee, A.; Blair, M.; Carter, L.; Chapin, F.S.; Fleming, P.; Ruffo, S.; Stults, M.; McNeeley, S.; et al. A comprehensive review of climate adaptation in the United States: More than before, but less than needed. Mitig. Adapt. Strateg. Glob. Chang. 2013, 18, 361-406. [CrossRef]

33. Dilling, L.; Lemos, M.C. Creating usable science: Opportunities and constraints for climate knowledge use and their implications for science policy. Glob. Environ. Chang. 2011, 21, 680-689. [CrossRef]

34. Harries, T.; Penning-Rowsell, E. Victim pressure, institutional inertia and climate change adaptation: The case of flood risk. Glob. Environ. Chang. 2011, 21, 188-197. [CrossRef]

35. Horvat, M.; Dubois, M.-C.; Snow, M.; Wall, M. International Survey about Digital Tools Used by Architects for Solar Design; T.41.B.2; International Energy Agency Solar Heating and Cooling Programme: Cedar, MI, USA, 2011.

36. McAndrews, C.; Deakin, E.; Schipper, L. Including climate change considerations in Latin American urban transport practices and policy agendas. J. Environ. Plan. Manag. 2013, 56, 674-694. [CrossRef]

37. Lemos, M.C.; Kirchhoff, C.J.; Ramprasad, V. Narrowing the climate information usability gap. Nat. Clim. Chang. 2012, 2, 789-794. [CrossRef]

38. Biesbroek, G.R.; Termeer, C.J.A.M.; Klostermann, J.E.M.; Kabat, P. Analytical lenses on barriers in the governance of climate change adaptation. Mitig. Adapt. Strateg. Glob. Chang. 2014, 19, 1011-1032. [CrossRef]

39. Nisbet, M.C. The ethics of framing science. In Communicating Biological Sciences: Ethical and Metaphorical Dimensions; Nerlich, B., Larson, B., Elliott, R., Eds.; Ashgate: London, UK, 2009; pp. 51-74.

40. Schön, D.A. The Reflective Practitioner: How Professionals Think in Action; Basic Books: New York, NY, USA, 1983.

41. Schön, D.A. Designing: Rules, types and words. Des. Stud. 1988, 9, 181-190. [CrossRef]

42. Augustin, S.; Coleman, C. The Designer's Guide to Doing Research: Applying Knowledge to Inform Design; John Wiley \& Sons: Hoboken, NJ, USA, 2012.

43. Markus, T.A. The role of building performance measurement and appraisal in design method. In Design Methods in Architecture; Broadbent, G., Ward, A., Eds.; Lund Humphries: London, UK, 1969; p. 204.

44. Darke, J. The primary generator and the design process. Des. Stud. 1979, 1, 36-44. [CrossRef]

45. Lloyd, P.; Scott, P. Discovering the design problem. Des. Stud. 1994, 15, 125-140. [CrossRef]

46. Cross, N. Designerly Ways of Knowing; Springer: London, UK, 2006.

47. Ala-Mantila, S.; Heinonen, J.; Junnila, S. Greenhouse Gas Implications of Urban Sprawl in the Helsinki Metropolitan Area. Sustainability 2013, 5, 4461-4478. [CrossRef]

48. Mohareb, E.A.; Mohareb, A.K. A comparison of greenhouse gas emissions in the residential sector of major Canadian cities. Can. J. Civ. Eng. 2014, 41, 285-293. [CrossRef]

49. Schiano-Phan, R.; Weber, F.; Santamouris, M. The mitigative potential of urban environments and their microclimates. Buildings 2015, 5, 783-801. [CrossRef]

50. Senbel, M.; Giratalla, W.; Zhang, K.; Kissinger, M. Compact Development without Transit: Life-Cycle GHG Emissions from Four Variations of Residential Density in Vancouver. Environ. Plan. A 2014, 46, 1226-1243. [CrossRef]

51. Kirkeby, I.M. Om at skabe arkitektfaglig viden. Nord. J. Archit. Res. 2012, 2, 70-90.

52. Dubois, C.; Cloutier, G.; Potvin, A.; Adolphe, L.; Joerin, F. Design support tools to sustain climate change adaptation at the local level: A review and reflection on their suitability. Front. Archit. Res. 2015, 4, 1-11. [CrossRef]

53. Horvat, M.; Kanters, J. Needs of Architects Regarding Digital Tools for Solar Building Design; T.41.B.4; International Energy Agency Solar Heating and Cooling Programme: Cedar, MI, USA, 2012; p. 10.

(C) 2016 by the authors; licensee MDPI, Basel, Switzerland. This article is an open access article distributed under the terms and conditions of the Creative Commons Attribution (CC-BY) license (http://creativecommons.org/licenses/by/4.0/). 